\title{
Ágape insípido: \\ Un cruce entre la estética del gusto y \\ la filosofía del cuerpo*
}

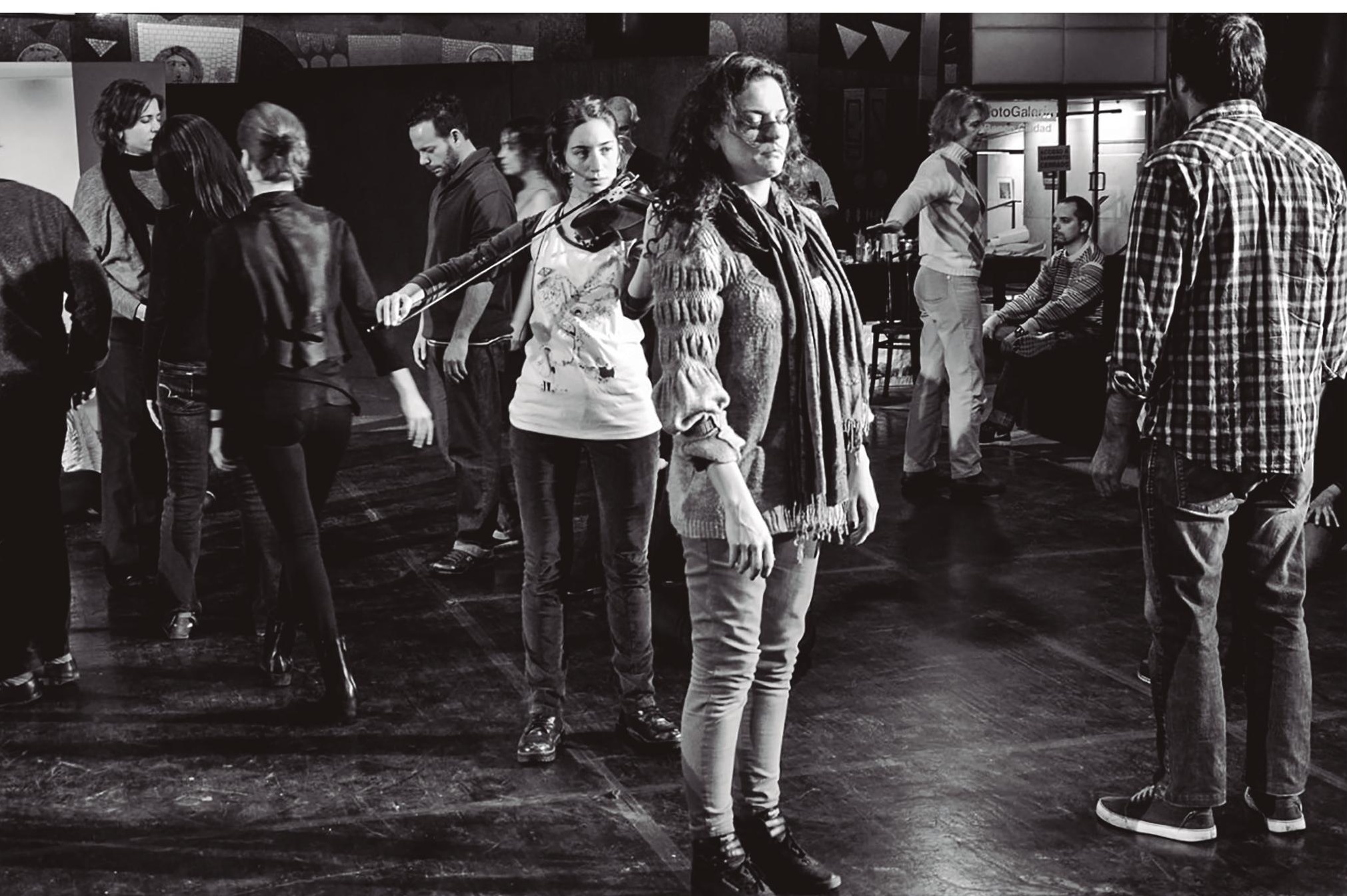




\title{
Ágape insípido: A cross between the aesthetic of taste and the philosophy of the body
}

\author{
Ágape insípido: Uma cruz entre a estética do gosto e a filosofia do corpo
}

\begin{abstract}
Vera Livia García Cassinelli**
Universidad Autónoma de Barcelona, España.

Correo electrónico: veraliviagarcia@gmail.com Página web: www.veraliviagarcia.com

Revista Corpo-grafías: Estudios críticos de y desde los cuerpos / Volumen 4 - Número 4 / Enero - diciembre de 2017 / ISSN impreso 2390-0288, ISSN digital 2590-9398 / Bogotá, D.C., Colombia / pp. 110-123.

Fecha de recepción: 3 de octubre de 2016

Fecha de aceptación: 15 de noviembre de 2016

Doi: https://doi.org/10.14483/25909398.13666

Cómo citar este artículo: García, V.L. (2017, enero-diciembre). Ágape insípido: un cruce entre la estética del gusto y la filosofía del cuerpo. Revista Corpo-grafías: Estudios críticos de y desde los cuerpos, 4(4), pp. 110-123 / ISSN 2390-0288.

*Artículo de investigación artística: el presente artículo se originó a partir de la tesis de máster en Investigación en Arte y Diseño "Ágape insípido, un aporte de conocimiento". Agradecimientos a Jèssica Jaques Pi y Gerard Vilar.

**Máster Oficial en Arte y Diseño (EINA), máster en Estética y Teoría del Arte Contemporáneo por la Universidad Autónoma de Barcelona (UAB). Licenciada en Artes del Espectáculo por la Universidad de Buenos Aires. Bailarina, performer, actriz. Trabaja en el campo de las artes escénicas como docente, creadora y directora artística.
\end{abstract}




\section{Resumen}

El presente artículo propone un recorrido sobre los puntos teóricos más significativos en el desarrollo del proyecto de investigación artística Ágape Insípido, que se originó a partir de la noción de lo insípido desarrollada por el sinólogo y filósofo francés François Jullien. El tema al que refiere se centra en lo insípido como condición de posibilidad en la práctica performativa, y manifiesta una necesidad personal de la autora de producir una hipótesis de trabajo que permita pensar posibles lugares de intersección y confluencia entre las diversas disciplinas, sean consideradas artísticas o no. El propósito de esta investigación es poder ampliar el conocimiento a partir de la performance participativa Ágape Insípido generando una articulación entre teoría y práctica artística como espacio fundamental desde donde pensar el arte contemporáneo.

Palabras clave: cuerpo, sabor, indeterminado, insípido, performance.

\section{Abstract}

The present article proposes a journey through the most important theoretical points in the development of the artistic and philosophical research project known as Insipid Banquet. It originated from the concept of blandness developed by French philosopher and sinologist François Jullien. The project focuses on insipidity as a condition of possibility in the practice of performance and expresses a need for the author to produce a working hypothesis that allows reflection on possible places of intersection and confluence between various disciplines. The purpose of Insipid Banquet is to create a connection between artistic theory and practice as a fundamental locus to elaborate a reflexion on contemporary art, and on performance as a defining part of it, by taking into account their interdisciplinary connection.

Keywords: body, flavor, indeterminate, insipid, performance.

\section{Resumo}

O artigo presente propõe uma análise sobre os pontos teóricos mais significativos no desevolvimento do Projeto de Investigação artística Ágape Insípido, um aporte de conhecimento. O tema refere-se a Insípido, como condição de possibilidade, na prática performática e manifesta uma nescessidade pessoal de produzir hipótese de trabalho, que permita pensar possíveis lugares de intersecção e confluência entre as diversas disciplinas, sejam consideradas artísticas ou não. 0 propósito desta investigação é poder ampliar o conhecimento a partir da performance participativa Ágape Insípido, gerando uma articulação entre teoria e prática artística,como espaço fundamental, desde onde pensar a arte contemporânea.

Palavras-chave: corpo, sabor, indeterminado, insípido, performance. 


\section{Introducción}

Ágape Insípido es un proyecto de investigación artística que se originó a partir de la noción de lo insípido desarrollada por el sinólogo y filósofo francés François Jullien (1998).

La hipótesis reflexiona acerca de la capacidad que posee el cuerpo insípido de transformarse ilimitadamente y develar multiplicidad de sentidos. De esta manera, se posiciona en un lugar de resistencia frente a la posibilidad de ser objeto de consumo. Resistencia otorgada por la propia condición de inestabilidad que le dispensa la capacidad de devenir siempre otro. El interés que despierta lo insípido reside en su carácter abierto, que le permite entretejer las fronteras de las diversas disciplinas artísticas. Cuestionando los preceptos de las mismas, que establecen una cierta distribución de lo pensable (Rancière, 2006).

Ágape Insípido se ha presentado en lugares tan diversos como en el Festival de Terrassa Noves Tendències ${ }^{1}$, en el Centro de Cultura Contemporánea de Barcelona ${ }^{2}$, en la Fundación Antoni Tàpies de Barcelona ${ }^{3}$, en el Centro Cultural de España en Buenos Aires ${ }^{4}$, en el Campus de Alimentación de Torribera de la Universidad de Barcelona ${ }^{5}$, en el Teatro de la Universidad Autónoma de Barcelona, en el Teatro General San Martín de Buenos Aires ${ }^{6}$ y en el Centro Cívico Cotxeres Borrell de Barcelona ${ }^{7}$. La última ejecución fue realizada con la participación de los alumnos de la Universidad de la Experiencia de Barcelona, en el marco del curso "Arte y Cocina".

\section{De lo insípido como indeterminado}

Lo insípido, desde Occidente, ha sido vinculado al ámbito de los sentidos, particularmente al del gusto. Según el diccionario de la Real academia Española, insípido, significa falto de sabor, que no tiene el grado de sabor que debiera o pudiera tener. Procede del latín insipidus, cuyo prefijo in expresa el valor contrario a la palabra, y la raíz sapo-oris: sabor. También aportan a la cuestión, los vocablos: sapiente: sabio y sápido: gustoso, ambos provenientes del verbo latino sapere que significa tener conocimiento, saber, o inteligencia; tanto como sabor o gusto. Es decir que en su origen, la palabra insípido, comprendía dos ámbitos a la vez: el sensitivo y el intelectual.

\footnotetext{
1. http://www.tnt.cat/es/tnt-espectacles/agape-insipido/

2. http://www.cccb.org/ca/activitats/fitxa/pensar-amb-la-llengua-i-el-paladar/223208

3. http://www.fundaciotapies.org/blogs/activitatsreactfeminism/?tribe_events=es-posible-un-cuerpo-insipido-hacia-una-experiencia-desde-la-practica-creativa-al-dialogo-con-la-teoria

4. http://www.cceba.org.ar/v3/ficha.php?id=1833

5. http://www.ub.edu/campusalimentacio/es/noticies/Arte_y_creatividad_UAB.html

6. http://complejoteatral.gob.ar/ver/rituales-de-pasaje/10007

7. http://w110.bcn.cat/portal/site/Eixample/menuitem.027460a126e8caa433433343a2ef8a0c/?vgnextoid=428a4ff09d371410VgnVCM1000001947900aRCRD\&vgnextchannel=0109484aaee59210VgnVCM10000074fea8c0RCRD\&vgnextfmt=formatDetall\&lang=es_ES
} 
En la práctica culinaria los sabores insípidos son reconocidos como aquellos difusos, evanescentes y sosos. La cocina china les concede un gran valor debido a su singular condición de indeterminabilidad. Al no pronunciar, distinguir o afirmar ningún sabor en detrimento de otro, contienen siempre algo a desarrollar dentro de los mismos, en forma de reserva, permaneciendo de este modo, implícitamente fértiles (Jullien, 1998).

Lo insípido en la cultura y el pensamiento chino trasciende el ámbito del gusto y se expande hacia la esfera artística, convirtiéndose en experiencia estética a través de las diversas artes como puedan ser la pintura, la música y la poesía (Jullien, 1998). Detenta un carácter nómada e indefinible. Y es por ello que, definirlo se vuelve una tarea compleja y aventurada, en el sentido de correr el riesgo de producir un discurso demasiado insistente y demostrativo que termine agrietando su propio modo de ser (García Cassinelli, 2014, pag. 17).

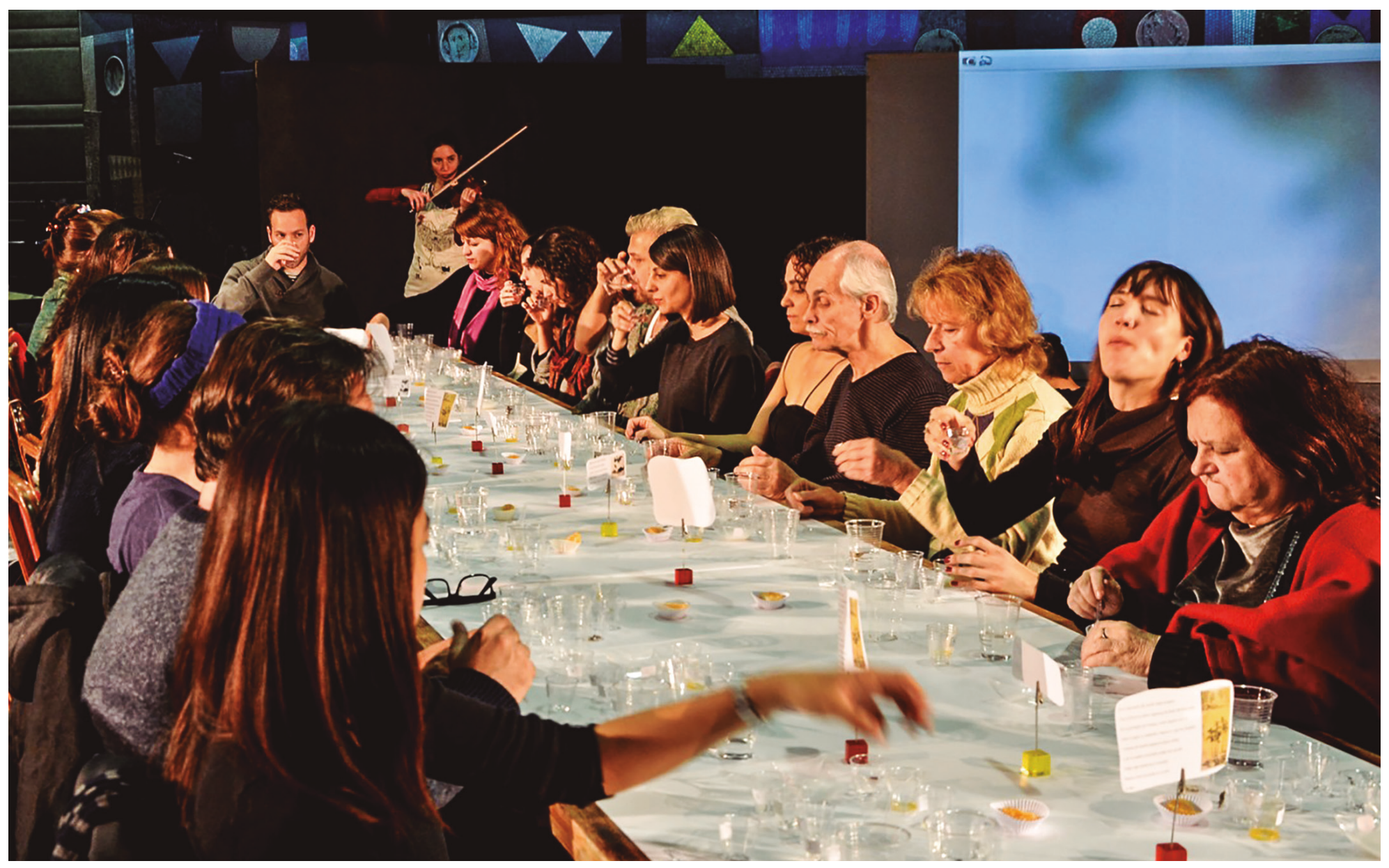

Irupé Tenetorio

Ciclo Rituales de Pasaje

Teatro General San Martín (2014) 
Se opone, pues, a la particularidad determinada de cualquier forma, trazo, movimiento, sonido, sabor, gesto; entendiendo que al privilegiar la atención e insistir en un sentido único, se produce una cancelación completa de este, excluyendo la posibilidad de cualquier otro devenir.

Jullien (1998) señala que la palabra china -dan- significa al mismo tiempo insipidez y desapego. Y en ese sentido cualquier sabor representa sólo una excitación momentánea que se desvanecería apenas consumido. De allí se puede comprender la frase: "El sabor nos ata, la insipidez nos desata" (1998, p.34). El sabor en su determinación, nos sujeta, acapara y deslumbra, produciendo una excitación inmediata, que apenas consumida se desvanece. En cambio lo insípido, al no estar atrapado por ningún gusto, posee la capacidad de transformación infinita, es inagotable, y se saborea lentamente dando toda su fuerza a la sensación (García Cassinelli, 2014, pag. 18).

Lo insípido nos mantiene en el campo de la experiencia sensible pero nos sitúa en el límite de su desdibujamiento, donde aquella se vuelve más tenue y desvaída. La forma que se diluye, el trazo difuminado, el movimiento esbozado, el residuo de un sonido, el gusto indefinido, el gesto inacabado, son todas manifestaciones de lo insípido en el arte, en cuanto conllevan en sí la capacidad de transformarse ilimitadamente. De esta manera lo inacabado se descubre como gesto voluntario. (García Cassinelli, 2014, p. 18).

Ahora bien, esta nueva mirada permite socavar la noción tradicional del concepto deshaciendo imposibilidades respecto a este. Por un lado, produce un desplazamiento del ámbito habitual de lo insípido -el gusto- permitiendo que se manifieste en el terreno de lo artístico. Y por el otro, posibilita descubrir una nueva cualidad de lo insípido, lo indeterminado. Pensar lo insípido como indeterminado permite descomponer la oposición binaria sápido-insípido y nos invita a reflexionar si la plenitud del sabor no es un efecto performativo del discurso que decide qué es sabor y qué no lo es (García Cassinelli, 2014, pag.19).

La división entre "dentro y fuera" (Fuss, 1995) funciona como forma para la significación y producción de sentido y al mismo tiempo designa una estructura de exclusión y exteriorización. Corresponde a un orden simbólico basado en una lógica de límites y fronteras. En nuestro caso, lo insípido se convierte en lo excluido -fuera del sabor- porque se relaciona con lo sápido, que sería lo que conforma la "norma". Lo insípido en relación con lo sápido, una exclusión interior, un (a) fuera que está dentro de la interioridad haciendo posible la articulación de esta última, una trasgresión de la frontera para constituir la frontera como tal (Fuss, 1995).

Por esta razón, considerar lo insípido como indeterminado permite desplazarnos a otro terreno, donde lo insípido ya no se configuraría como un (a) fuera del sabor, sino como un sabor que se mantiene en el borde, un "todavía no" o un "ya se está yendo". De este modo, abre el camino hacia una realidad inestable, difusa y transitoria. Una realidad en la que colapsan las fronteras y desaparecen los límites (García Cassinelli, 2014, pag. 20). 


\section{Proceso creativo}

Durante la elaboración de la propuesta se fueron visualizando una serie de tensiones que se articulaban alrededor de este concepto: La posibilidad de comprobar en la praxis que lo insípido se constituía en una categoría de cruce, traspasando las fronteras entre las diversas disciplinas artísticas. La viabilidad de concebir lo insípido como una cualidad que nos permitiría resistir desde la indeterminación; la cancelación de un sentido único. Y la posibilidad de que esta cualidad en el cuerpo manifestara el tránsito por lugares de fragilidad, disolución, rendición, invitando a desarticular la inercia habitual e insistiendo la posibilidad de ser otro con otros (García Cassinelli, 2014, pag. 21).

A medida que se fue avanzando en el entramado de los ejes teóricos con la práctica fue creciendo la intención de abordar lo insípido desde diferentes disciplinas. Algunas prácticas culinarias centran su investigación en la exploración de los procesos sensoriales que se ponen en marcha durante la creación y degustación de un nuevo plato. Colores, formas, texturas, temperaturas, olores y sonidos se combinan, constituyendo una experiencia holística de los sentidos. De esta manera, y en sucesivos intercambios con Jaques Pi (directora de mi tesis de máster), surgió la idea de convocar e incorporar a la investigación un cocinero, Castro (jefe de cocina del restaurante El Bulli), con el objetivo de generar un espacio de experimentación y cruce entre diferentes lenguajes a partir del concepto (García Cassinelli, 2014, pag. 21).

Considerando la cantidad de variables que se iban incorporando, pensé en trabajar una práctica artística híbrida que nos permitiera movernos en un terreno sin límites fijos. El campo de la performance tiene como objeto de estudio "los géneros estéticos del teatro, la danza y la música, pero no se limita a ellos; comprende también ritos ceremoniales humanos y animales, seculares y sagrados, representación y juego, performance de la vida cotidiana; acción política (...)" (Schechner, 2000, p. 11). El performance es un género impuro "surge de varias prácticas artísticas, pero trasciende sus límites; combina muchos elementos para crear algo inesperado, chocante, llamativo" (Taylor, 2012, p. 11).

Los propósitos fueron poder dar visibilidad a la pregunta sobre lo insípido en el cuerpo mediante la experiencia estética, complejizándolo, volviéndolo físicamente presente. Por ello se decidió que el público participante fuera parte de la escena, ocupando el lugar del productor de conocimiento (García Cassinelli, 2014, p. 22).

A partir de la creación de una situación específica: el banquete, se invitaría a un grupo de personas a la Fundación Antoni Tàpies ${ }^{8}$ a participar de una experiencia en la que el público se transformaría desde el inicio en el protagonista de la acción. De esta manera, se produciría una oscilación de las oposiciones dicotómicas actor-espectador; arte-

8.http://www.fundaciotapies.org/blogs/activitatsreactfeminism/?tribe_events=es-posible-un-cuerpo-insipido-hacia-una-experiencia-desde-la-practica-creativa-al-dialogo-con-la-teoria 


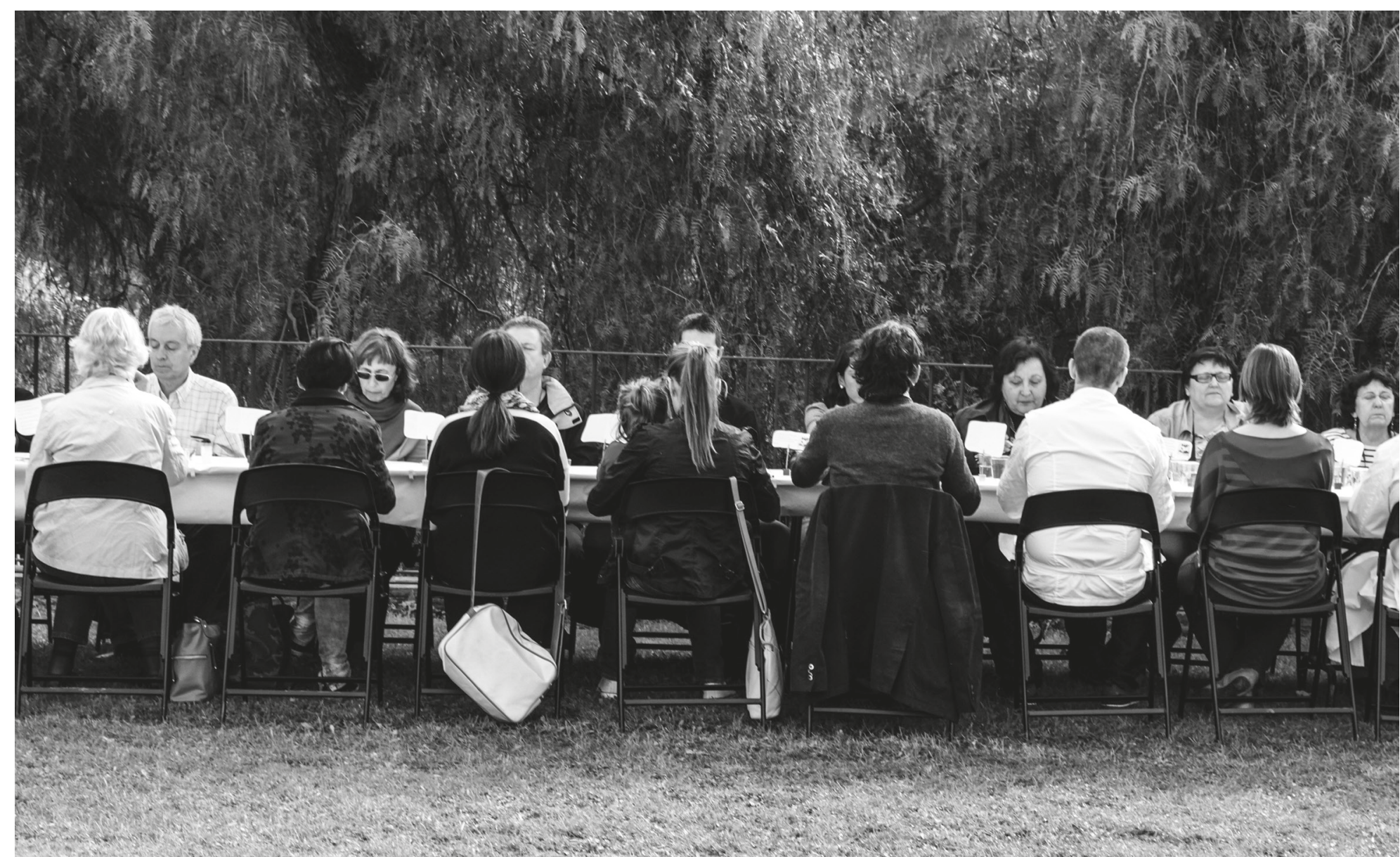

Ana Pozo Rivas

ExpAliments

Universidad de Barcelona (2013)

realidad; sujeto-objeto; sápido-insípido y se daría paso a una realidad inestable y ambigua. Los comensales se experimentarían como perceptores activos y al mismo tiempo como afectados por lo percibido. La performance consistía en un viaje gustativo de lo insípido a lo sápido a través de los sentidos y del cuerpo en movimiento que se dividía en tres partes. "La entrada" se presentaba como una invitación a degustar diferentes sabores -desconocidos a priori- con el objetivo de provocar un devenir sensorial y neutralizar la tendencia a permanecer cautivos por un sabor determinado, una imagen o sensación. A partir de allí, se pondría en marcha el bucle autopoiético, de retroalimentación, que funciona como un sistema que se reorganiza a sí mismo, integrando constantemente elementos impredecibles. Los participantes se exponen y asumen su responsabilidad en una situación que no han creado, pero que por su participación se ven involucrados. Afectan a los otros comensales con sus acciones y a 
su vez, son afectados por estos. Durante el "plato principal" se invitaría a los comensales a dejar la mesa y poner el cuerpo en movimiento a partir de un nuevo estado de disponibilidad. Y para finalizar, con "la sobremesa", se inauguraría un diálogo con los participantes. La propuesta del Ágape Insípido pone en juego tres de los aspectos vinculados a la condición de acontecimiento de la realización escénica: la desestabilización de las oposiciones, dicotómicas, la autopoiesis del bucle de representación y las situaciones de liminalidad (Fischer-Lichte, 2004, p. 328). De esta forma se aleja de la idea de obra entendida como artefacto estable sobre el cual el receptor realiza sus operaciones hermenéuticas. Presenta un carácter efímero e irrepetible y su materialidad se produce al generarse performativamente la corporalidad, la espacialidad y la sonoridad.

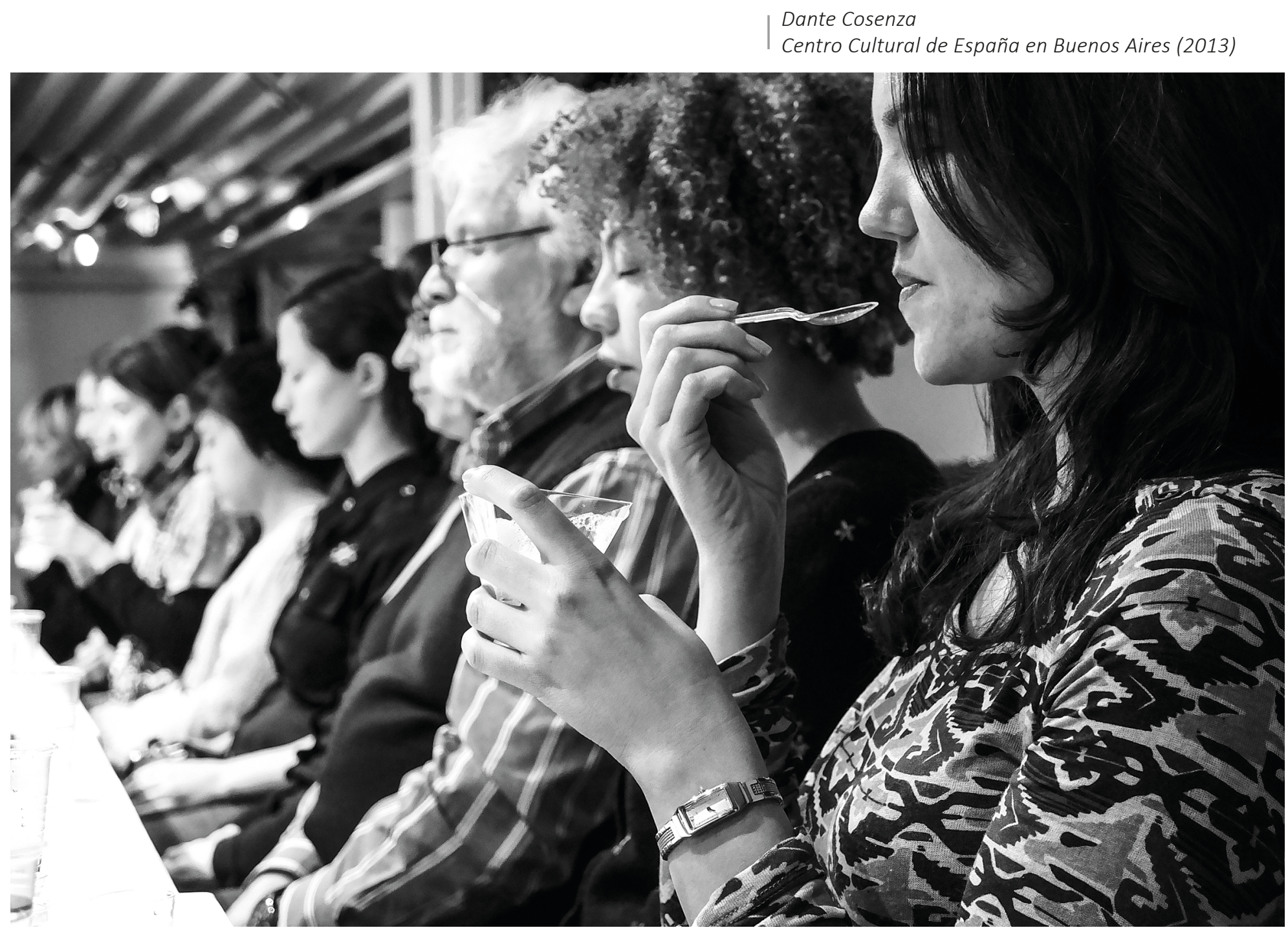


En el caso específico que tuvo como ámbito la Universidad de la Experiencia se acompañó el desarrollo del ágape, con frecuencias sonoras ejecutadas en vivo por el artista Marco Bellonzi. La degustación comenzó con un aperitivo de sabor neutro -gelatina de agua- mientras que los cinco siguientes contenían además los gustos básicos (dulce, salado, ácido, amargo, picante). A posteriori se degustaron dos alimentos insípidos de texturas diferentes (obulato y espuma de aire), y luego los cinco sabores básicos (azúcar de merara, sal de anchoas, agua tónica, frutos de la pasión y aceite de guindilla). La entrada cerraba con el gajo de un cítrico modificado, al que se le incorporó sal y un aceite de frutos secos con la intención de que contuviera los cinco gustos básicos. En la tercera fase, se invitó a los participantes a dialogar a partir de la experiencia acontecida.

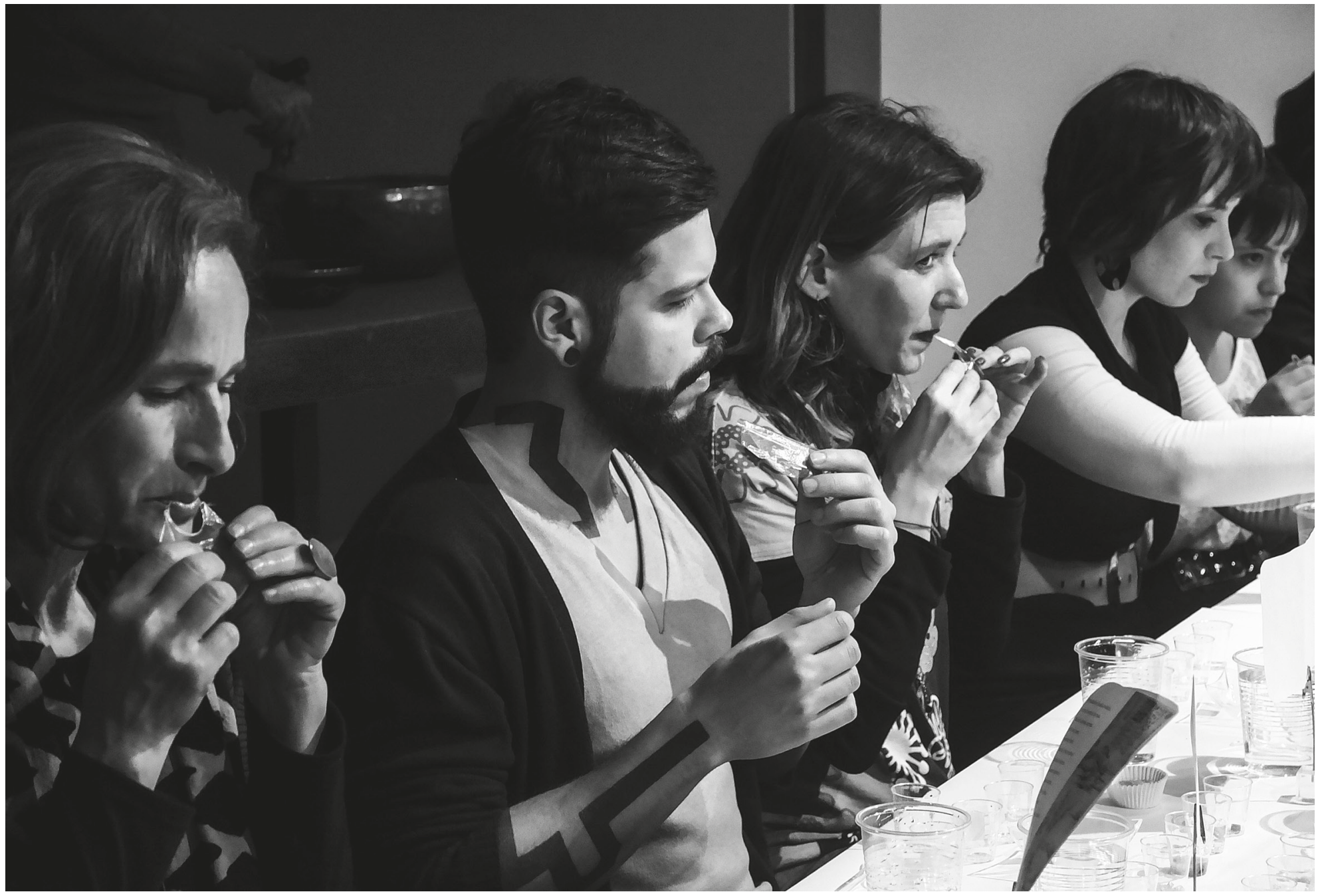


La performance Ágape Insípido ha sido realizada en contextos muy diversos y, en tanto proyecto participativo, los ámbitos de presentación adquieren una especial relevancia, estableciéndose una relación directa entre dichos contextos y la composición de los grupos sociales participantes. Algunas de las derivaciones colectivas extraídas del intercambio con los participantes fueron: el carácter corporal de la degustación, el despertar de los sabores en el cuerpo; el tema del vacío y la disponibilidad corporal a partir de la experiencia, la particularidad de cada sabor percibida de manera segmentada en el cuerpo; el enigma del sabor en el cuerpo, la experimentación de los cinco sabores al mismo tiempo, el carácter efímero del sabor, la problemática cultural respecto a la relación con lo insípido; las expectativas respecto al sabor y al "por venir", el estado de contemplación, la atención sensible, el asco, el rechazo por miedo a lo desconocido y el descubrimiento de nuevos espacios en el cuerpo a partir del "no sabor".

Si bien en cada una de las experiencias se abrieron nuevas reflexiones en torno a lo insípido en el cuerpo, el aspecto considerado más relevante de los señalados ha sido el carácter liminal de la experiencia vinculado a la sensación de inestabilidad y ambigüedad vivenciada por los participantes, que ha ido acompañada de cambios energéticos, afectivos, psicológicos y motores. La performance interpela el cuerpo. ¿De qué manera?

\section{Del sabor (in)cógnito del cuerpo}

"Cuerpo tocado, tocante, frágil, vulnerable, siempre cambiante, huidizo, inasible, evanescente ante la caricia o el golpe, cuerpo sin corteza, pobre piel tendida en una caverna donde flota nuestra sombra” (Nancy, 2004, p. 33).

Los comensales ingresan a la performance y se sientan juntos en una gran mesa. Este cuerpo visible, puede mirar y ser mirado por el resto de los participantes. La mesa compartida inaugura una nueva utopía (Foucault, 2010), la del cuerpo grupal: La posibilidad de ser otro con los otros. El cuerpo (re)ligado a otros cuerpos, y a otras partes del mundo (Foucault, 2010). En el comienzo de la performance se invita a los participantes a realizar la degustación con ojos cerrados, produciendo una desjerarquización del sentido de la vista, que le hace perder su supremacía en el orden del conocimiento. La atención, entendida como la apertura-entre que permite la producción de nuevos gestos en un reagenciamiento del pasado que se actualiza al diferenciarse en el presente (Bardet, 2012), se reparte entre el resto de los sentidos -gustativo, olfativo, táctil y auditivo-cobrando presencia otros lugares del cuerpo: La lengua, las papilas gustativas, la boca, los labios, la musculatura de la cara, la piel, la espalda, los oídos y la nariz. Dicha privación momentánea de uno de los sentidos conduce a una diseminación de los lugares del hacer y el sentir, desarticulando gestos y lugares normalmente significantes (Bardet, 2012). Al deshacerse de ciertos modos habituales de paladear y percibir a través del cuerpo, los comensales se vuelven vulnerables. En el degustar de los sabores se abre un proceso indeterminado de sensaciones cambiantes. 
Es en la repetición continua de la acción, que el cuerpo se sustrae poco a poco de su visibilidad y accede a ciertos lugares donde están guardados los registros previos a la palabra. Donde el cuerpo es solo cuerpo despojado de palabra (García, Cassinelli, 2014, p. 77). "Sentir que mi cuerpo vive y verlo en movimiento me procura la certeza inmediata de ser yo mismo, certeza que sin embargo oculta mi ignorancia de quién soy y de dónde vengo" (Nasio, 2008). El yo es al propio tiempo la certeza de ser uno mismo y la ignorancia de lo que uno es. Por eso Lacan califica al yo como "lugar de desconocimiento".

Centro Cultural de España en Buenos Aires (2013)

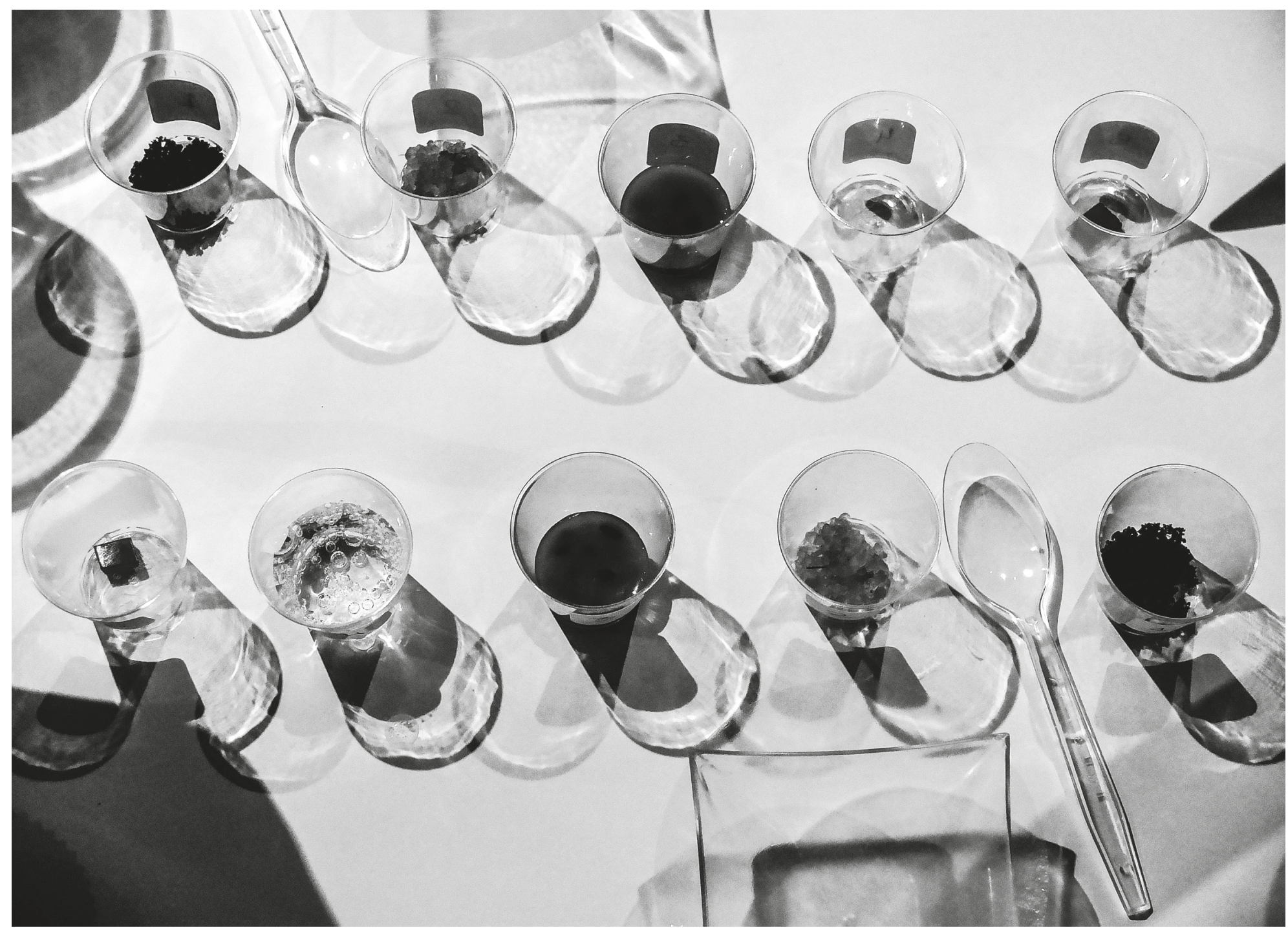


En el transcurrir de la degustación, el cuerpo tópico real deviene opaco, misterioso y se (re)vela, a partir de la percepción de los estímulos gustativos y sonoros, como cuerpo utópico (Foucault, 2010). Cuerpo permeable a los otros cuerpos, a los sabores, texturas, sonidos, y al mismo tiempo cuerpo impenetrable. Multiplicidad de lugares visibles e invisibles de los que no se puede separar al cuerpo y que se vuelven más evidentes durante la performance. ¿Acaso puedo ver mi espalda, mi cráneo o mis isquiones? Los sabores irrumpen y resuenan en él conduciéndolo hacia otro espacio. Un espacio que no es exterior sino que el propio cuerpo articula y proyecta (Foucault, 2010).

Durante la fase de movimiento, los participantes son convidados a caminar y moverse por el espacio con ojos cerrados a partir de un nuevo estado de disponibilidad. El cuerpo dilatado, según todo un espacio que le es interior y exterior a la vez, revela una "enérgica capacidad para la acción que se muestra como velada por una forma de pasividad" (Barba, 1987). Esta privación del sentido de la vista implica, necesariamente, una desaceleración del movimiento y tiene el objetivo de inducir al cuerpo a un tipo de atención sensible respecto al resto de los sentidos durante el caminar. Un caminar común, anónimo y singular a la vez. La desaceleración genera al mismo tiempo la posibilidad de percibir la "relación gravitatoria" (Bardet, 2012) de atracción mutua entre cuerpo-tierra, la relación del cuerpo en el espacio, y de los diferentes cuerpos entre sí. En este caminar los cuerpos se perciben, se rozan, se cruzan, se contactan y se contaminan, volviendo sus contornos cada vez más inestables. Evidencian un exceso de sentido imposible de saturar (Nancy, 2004). Es en la atención sensible del caminar donde puede emerger lo imprevisible.

La experiencia del Ágape Insípido al poner el cuerpo en movimiento a partir de un cambio sensorial -ojos cerradospropone una mutación del orden habitual de los sentidos y se conforma como terreno de emergencia del elemento utópico del cuerpo. De esta manera, devela el carácter indeterminado del mismo y produce una apertura hacia otras posibilidades de ser y estar en el mundo. Con cada nueva performance se presenta una nueva utopía superadora de la topía repetitiva (García Cassinelli, 2014, p. 79).

La performance, en tanto realización escénica ritualizada, es un volver a poner en obra y un volver a experimentar un repertorio de significados socialmente establecidos de antemano. $Y$ en esta repetición se incluye, a su vez, la posibilidad de la fisura y el cambio. Se ponen en marcha procesos activos de corporización, vinculados a la noción de "experiencia vivida" expuesta por Merleau Ponty (García Cassinelli, 2014, p. 80).

Es decir, el cuerpo fenoménico, el ser-en-el mundo, donde la experiencia de la percepción corporal del sujeto se vuelve vehículo para llegar al mundo. "El cuerpo es nuestro anclaje en el mundo" (1993) [1945]. El cuerpo se plantea como la condición de posibilidad de cualquier producción cultural. Con cada movimiento el cuerpo se convierte en otro, se corporiza como algo nuevo y se descubre al cuerpo como una incesante y continúa materialización de posibilidades. 


\section{Referencias}

Bardet, M. (2012). Pensar con mover: un encuentro entre danza y filosofía. Buenos Aires: Cactus.

Fischer-Lichte, E. (2011). Estética de lo performativo. (Trad. Diana González Martín y David Martínez Perucha). España: Abada Editores.

Foucault, M. (2010). El cuerpo utópico: Las heterotopías. Buenos Aires: Nueva Visión.

Fuss, D. (1995). Dentro/Fuera. En Carhy Caruth \& Deborah Esch (Eds.). Critical encounters. Reference and responsability in deconstructive writing.(Trad. de Meri Torras). New Brunswich, New Jersey: Rutgers University Press.

García Cassinelli, V. L. (2014). “Ágape” Insípido, un aporte de conocimiento. EINA. Recuperado de: http://diposit.eina.cat/bitstream/ handle/20.500.12082/395/tfm_2013_2014_garcia_vera_livia.pdf?sequence=1\&isAllowed=y

Jullien, F. (1998). Elogio de lo insípido, A partir de la estética del pensamiento chino. (Trad. de Anne-Helene Suarez). España: Siruela S.A.

Merleau-Ponty, M. (1970) (1964). Lo visible y lo invisible. Barcelona: Empresa Editorial.

Merleau-Ponty, M. (1993). Fenomenología de la percepción. Buenos Aires: Planeta [1945].

Nancy, J. L., (2004). 58 Indicios sobre el cuerpo: Extensión del alma. (Trad. Daniel Alvaro). Buenos Aires: La Cebra.

Nasio, J. D. (2008). Mi cuerpo y sus imágenes. Argentina: Paidós.

Rancière; J. (2006). Penser entre les disciplines. Une esthétique de la connaissance. Inaesthetik, 0, 81-102.

Schechner, R. (2000). Performance. Teoría y prácticas interculturales. (Trad. M Ana Diz). Buenos Aires: Libros del Rojas. Universidad de Buenos Aires.

Taylor, D. (2012). Performance. Buenos Aires: Asunto Impreso. 


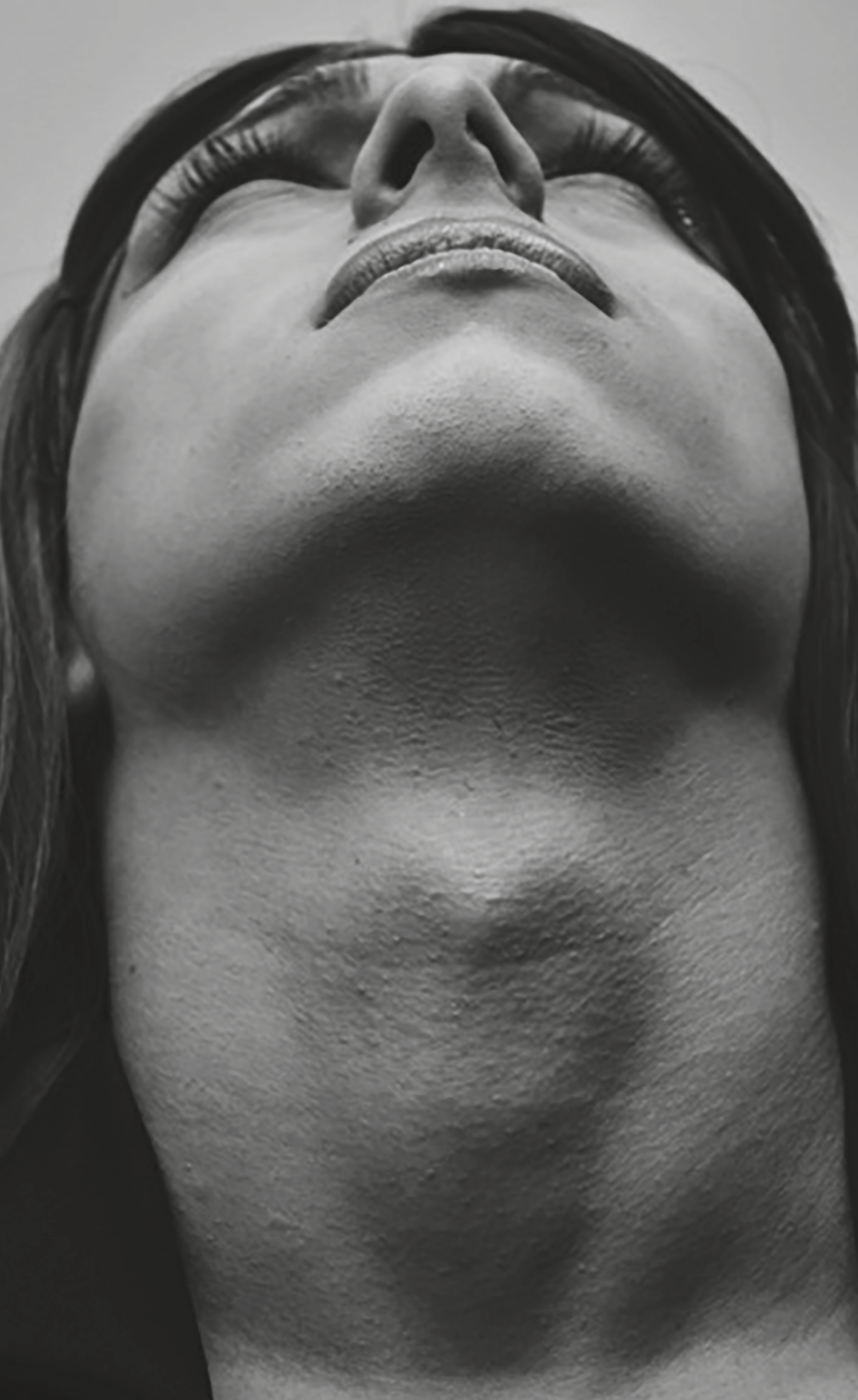

Fotografías por: Ligeya Daza

Hernández

Título: TRANSPARENCIAS

Año: 2011

Fotografías de Mujeres Trans para la realización de un calendario TRANS en la Localidad de los Mártires, Bogotá: estas fotografías fueron tomadas en el marco de la realización de la serie TRANSPARENCIAS, Beca en creación (fotográfica) de la SECRETARIA DE CULTURA RECREACION Y DEPORTE (SCRD) Convocatorias Amor por Bogotá, Localidades culturalmente activas. 